\title{
Synthesis of tricyclic isoindoles and thiazolo[3,2-c][1,3]benzoxazines
}

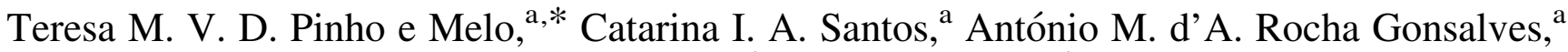 \\ José A. Paixão ${ }^{b}$ and Ana M. Beja ${ }^{b}$ \\ ${ }^{a}$ Departamento de Química, Universidade de Coimbra, Rua Larga, 3004-535 Coimbra, Portugal \\ ${ }^{\mathrm{b}}$ Departamento de Física, Universidade de Coimbra, 3004-516 Coimbra, Portugal
}

Received 21 January 2004; revised 21 January 2004; accepted 11 March 2004

\begin{abstract}
The thermolysis of $(3 R, 9 \mathrm{~b} S)$-5-oxo-2,3,5,9b-tetrahydrothiazolo[2,3- $a$ ]isoindole-3-carboxylic acids in $\mathrm{Ac}_{2} \mathrm{O}$ led to novel 3-methylene-2,5-dioxo-3H,9bH-oxazolo[2,3- $a$ ]isoindoles and chiral (9bS)-5-oxo-2,3,5,9b-tetrahydrothiazolo[2,3- $a$ ]isoindoles were obtained on FVP. Starting from L-cysteine methyl ester $(3 R, 10 \mathrm{~b} R)-5$-oxo-2,3-dihydro- $10 \mathrm{~b} H$-[1.3]thiazolo[3,2-c][1,3]benzoxazines were obtained as single stereoisomers. The thermolysis of $(3 R, 10 \mathrm{~b} R)$-5-oxo-2,3-dihydro- $10 \mathrm{~b} H$-[1.3] thiazolo[3,2-c][1,3]benzoxazine-3-carboxylic acid in $\mathrm{Ac}_{2} \mathrm{O}$ gave 5-acetyl-2-phenyl-2,3-dihydrothiazole. The structures of methyl $(3 R, 9 \mathrm{~b} S)$-5-oxo-2,3,5,9b-tetrahydrothiazolo[2,3$a$ ]isoindole-3-carboxylate 1a and methyl $(2 R, 4 R)$ - $N$-chlorocarbonyl-2-(2-hydroxyphenyl)thiazolidine-4-carboxylate 9 were determined by X-ray crystallography.

(C) 2004 Elsevier Ltd. All rights reserved.
\end{abstract}

\section{Introduction}

The study of 1,3-dipolar cycloaddition of münchnones as an approach to chiral pyrrolo[1,2-c]thiazoles is an area of our current research interests. ${ }^{1}$ In this context we became interested in exploiting the possibility of preparing 1,3thiazolidine-4-carboxylic acids fused to five- and sixmembered ring systems which could be used as potential münchnone precursors.

In a preliminary communication, we described the thermolysis $(3 R, 9 \mathrm{~b} S)-5$-oxo-2,3,5,9b-tetrahydrothiazolo[2,3-a]isoindole-3-carboxylic acids in acetic anhydride where no evidence for the generation of mesoionic species was observed. However, this study led to the development of a synthetic methodology to 3-methylene-2,5-dioxo$3 H, 9 \mathrm{~b} H$-oxazolo[2,3-a]isoindoles. ${ }^{2}$ In this paper we report full details of the work on the synthesis and reactivity of 5-oxo-2,3,5,9b-tetrahydrothiazolo $[2,3-a]$ isoindole-3-carboxylic acids as well as of 5-oxo-2,3-dihydro- $10 \mathrm{bH}$ [1.3]thiazolo[3,2-c][1,3]benzoxazine derivatives.

\section{Results and discussion}

The reaction of L-cysteine methyl ester with 2-carboxy-

Keywords: Diastereoselectivity; Thiazolo[2,3-a]isoindoles; 3-Methylene2,5-oxazolo[2,3-a]isoindoles; [1.3] Thiazolo[3,2-c][1,3]benzoxazines.

* Corresponding author. Tel.: +351-239-852080; fax: +351-239-826068; e-mail address: tmelo@ci.uc.pt benzaldehyde was carried out following the general procedure reported earlier for the synthesis of thiazolidines. ${ }^{3}$ The product was purified simply by recrystallisation. This resulted in the direct diastereoselective synthesis of methyl $(3 R, 9 \mathrm{~b} S)-5$-oxo-2,3,5,9b-tetrahydro-thiazolo[2,3$a$ ] isoindole-3-carboxylate 1a in 71\% yield (Scheme 1).

The structure of 1a was confirmed by X-ray crystallography (Fig. 1). The absolute structure was determined by a Flack analysis (898 Friedel pairs, $\eta=0.01(3)$ ) that unambiguously assigns the $R, S$ configuration to the chiral centers $\mathrm{C} 3$ and C9b.

Compound 1a was converted into the corresponding acid 2a in $91 \%$ yield $\left([\alpha]_{\mathrm{D}}^{25}=-343, c=0.1\right.$, EtOH $)$ by the reaction with lithium iodide in ethyl acetate and treatment with aqueous $\mathrm{HCl}$ (Scheme 1).

Compound 2a can also be prepared as described by Oliver et al. directly from the reaction of 2-carboxybenzaldehyde with cysteine hydrochloride in the presence of pyridine. ${ }^{4}$ This procedure gave 5-oxo-2,3,5,9b-tetrahydrothiazolo[2,3a] isoindole-3-carboxylic acid $\mathbf{2 a}$ in $58 \%$ yield.

The reactivity of compound $\mathbf{2 a}$ as a münchnone precursor was studied. Attempts were made to promote cyclodehydration by heating at reflux a solution of compound 2a in acetic anhydride in the presence of dimethyl acetylenedicarboxylate. However, the expected $1 \mathrm{H}, 3 \mathrm{H}$ pyrrolo[1,2-c]thiazole was not obtained even when prolonged heating was used. 


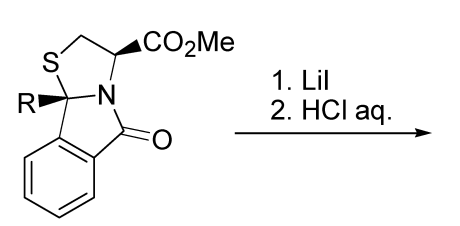

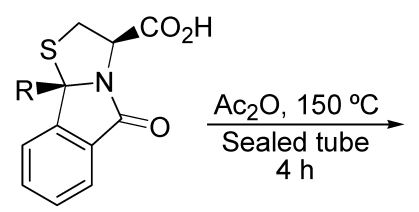

2a, $\mathrm{R}=\mathrm{H} \quad 91 \%$

2b, $\mathrm{R}=\mathrm{CH}_{3} \quad 85 \%$

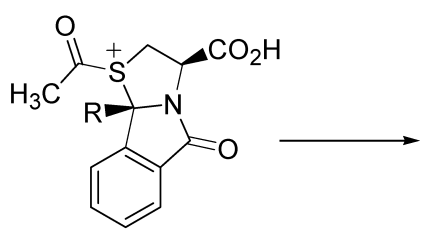

3a, $\mathrm{R}=\mathrm{H}$

$3 \mathbf{b}, \mathrm{R}=\mathrm{CH}_{3}$

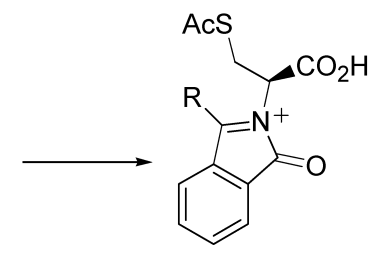

4a, $\mathrm{R}=\mathrm{H}$

4b, $\mathrm{R}=\mathrm{CH}_{3}$
$-\mathrm{AcSH}$<smiles>[R]C1=[N+](C(=C)C(=O)O)C(=O)c2ccccc21</smiles>

5a, $\mathrm{R}=\mathrm{H}$

$5 \mathbf{b}, \mathrm{R}=\mathrm{CH}_{3}$<smiles>[R]C12OC(=O)C(=C)N1C(=O)c1ccccc12</smiles>

6a, $\mathrm{R}=\mathrm{H}$

$6 \mathbf{b}, \mathrm{R}=\mathrm{CH}_{3}$
$37 \%$

$64 \%$

Scheme 1.

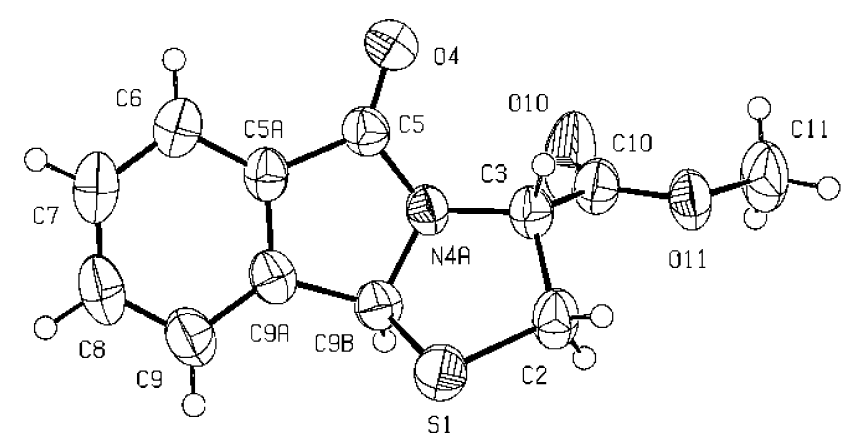

Figure 1. X-ray structure of compound 1a.

Based on the structure of methyl $(3 R, 9 \mathrm{~b} S)-5$-oxo-2,3,5,9btetrahydrothiazolo[2,3-a]isoindole-3-carboxylate 1a, determined by X-ray crystallography, we can explain this unsuccessful result. This tricyclic compound has a rigid structure and is characterized by having a value of $122.42^{\circ}$ for the $\mathrm{C} 5-\mathrm{N} 4 \mathrm{~A}-\mathrm{C}-3$ bond angle (Fig. 1 and Table 1). A similar bond angle is expected for $(3 R, 9 \mathrm{~b} S)-5$-oxo-2,3,5,9btetrahydrothiazolo[2,3-a]isoindole-3-carboxylic acid $\mathbf{2 a}$. The C-5, N-4A and C-3 atoms would be part of the mesoionic ring and a significant structure distortion had to occur in order to allow its formation. Thus, the generation of a münchnone from compound $\mathbf{2} \mathbf{a}$ is not a favourable process.

Table 1. Bond angles $\left(^{\circ}\right)$ for compound 1a

\begin{tabular}{llll}
\hline C2-S1-C9B & $88.93(12)$ & C5-N4A-C9B & $111.93(19)$ \\
C9B-N4A-C3 & $115.55(18)$ & N4A-C9B-C9A & $103.77(19)$ \\
N4A-C9B-S1 & $104.45(16)$ & N4A-C5-C5A & $106.3(2)$ \\
C3-C2-S1 & $106.91(17)$ & C9A-C5A-C5 & $108.9(2)$ \\
N4A-C3-C2 & $107.12(19)$ & C5A-C9A-C9B & $108.6(2)$ \\
C5-N4A-C3 & $122.42(19)$ & C9A-C9B-S1 & $115.57(18)$ \\
\hline
\end{tabular}

Nevertheless, we carried out the reaction of $(3 R, 9 \mathrm{~b} S)-5$-oxo2,3,5,9b-tetrahydrothiazolo[2,3-a]isoindole-3-carboxylic acid 2a with acetic anhydride and dimethyl acetylenedicarboxylate in a sealed tube. The solution was heated at $150{ }^{\circ} \mathrm{C}$ for $4 \mathrm{~h}$. Although no 1,3-dipolar cycloadduct was obtained, 3-methylene-2,5-dioxo-3H,9bH-oxazolo[2,3a]isoindole $6 \mathbf{6}$ was isolated in $37 \%$ yield which (Scheme 1). The structure of $\mathbf{6 a}$ was determined by X-ray crystallography. ${ }^{2}$

The mechanism proposed for the formation of compound $\mathbf{6 a}$ is outlined in Scheme 2. The process can be regarded as involving the formal elimination of the elements of $\mathrm{SH}$ from $(3 R, 9 \mathrm{~b} S)-5$-oxo-2,3,5,9b-tetrahydrothiazolo[2,3-a]isoindole-3-carboxylic acid 2a leading to $N$-acyliminium ion 5a followed by a 5-endo-trig cyclization. It represents the synthesis of an isoindole derivative (6a), a new member to a class of compounds having a significant number of applications. $^{5}$

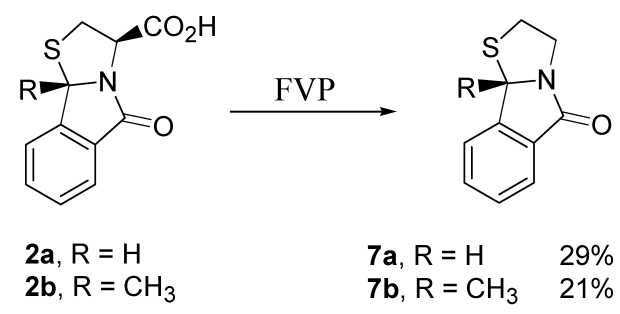

Scheme 2.

In order to determine the scope of this route to 3-methylene2,5-dioxo-3H,9bH-oxazolo[2,3- $a$ ]isoindoles we prepared (3R,9bS)-9b-methyl-5-oxo-2,3,5,9b-tetrahydrothiazolo[2,3a] isoindole-3-carboxylic acid $\mathbf{2 b}$ (Scheme 1). The reaction of L-cysteine methyl ester with 2-acetylbenzoic acid was carried out in presence of sodium acetate in refluxing toluene for $5 \mathrm{~h}$ giving $(3 R, 9 \mathrm{~b} S)-9 \mathrm{~b}$-methyl-5-oxo-2,3,5,9btetrahydrothiazolo[2,3-a] isoindole-3-carboxylate $\mathbf{1 b}$ in $75 \%$ yield with the value of $[\alpha]_{\mathrm{D}}^{25}=-328.7\left(c=1.75, \mathrm{CH}_{2} \mathrm{Cl}_{2}\right)$. Compound $\mathbf{2 b}$ was obtained from $\mathbf{1 b}$ in $85 \%$ yield.

We carried out the reaction of $(3 R, 9 \mathrm{~b} S)-9 \mathrm{~b}-$ methyl-5-oxo2,3,5,9b-tetrahydrothiazolo[2,3-a]isoindole-3-carboxylic acid $\mathbf{2 b}$ with acetic anhydride in a sealed tube (Scheme 1). The solution was heated at $150{ }^{\circ} \mathrm{C}$ for $4 \mathrm{~h}$. In a process 
analogous to that described for the synthesis of oxazolo[2,3a] isoindole derivative $\mathbf{6 a}$, compound $\mathbf{2 b}$ was converted into the tricyclic isoindole derivative 9b-methyl-3-methylene2,5-dioxo-3H,9b $H$-oxazolo[2,3-a] isoindole $\mathbf{6 b}$ in $64 \%$ yield. When the reaction of $\mathbf{2} \mathbf{b}$ with acetic anhydride was performed in the presence of dimethyl acetylenedicarboxylate (sealed tube, $150{ }^{\circ} \mathrm{C}, 4 \mathrm{~h}$ ) compound $\mathbf{6 b}$ was isolated in lower yield $(40 \%)$ but no 1,3-dipolar cycloadduct was formed.

The flash vacuum pyrolysis of $(3 R, 9 \mathrm{~b} S)-5$-oxo- $2,3,5,9 \mathrm{~b}-$ tetrahydrothiazolo[2,3-a]isoindole-3-carboxylic acids 2a and $\mathbf{2 b}$ was also studied (Scheme 2). We found that on FVP $\left(600{ }^{\circ} \mathrm{C} / 3 \times 10^{-2}-4 \times 10^{-2}\right.$ mbar $)$ these compounds undergo decarboxylation to the corresponding chiral (9bS)-5-oxo-2,3,5,9b-tetrahydrothiazolo[2,3-a]isoindoles (7a and $7 \mathbf{b})$ in moderate yields.

Compounds 7a and $\mathbf{7 b}$ have been prepared before from the reaction of carboxybenzaldehyde or 2-acetylbenzoic acid with 2-aminoethanethiol. However, they were obtained as racemic mixtures. ${ }^{4,6,7}$ Some 5-oxo-2,3,5,9b-tetrahydrothiazolo[2,3-a]isoindoles substituted at C-9 with aryl and heteroaromatic groups have also been prepared as racemic mixtures although the separation of both enantiomers can be achieved by chromatography on cellulose triacetate. ${ }^{5 b}$

Our synthetic procedure is particularly interesting since it allows the synthesis of $(9 \mathrm{~b} S)$-5-oxo-2,3,5,9b-tetrahydrothiazolo[2,3-a]isoindoles directly as single enantiomers.

We then went on to investigate the possibility of preparing a tricyclic compound having a thiazolidine ring fused to a sixmembered ring which should be a better münchnone precursor in terms of structural requirements than 5-oxo2,3,5,9b-tetrahydrothiazolo[2,3-a]isoindoles $\mathbf{2 a}$ and $\mathbf{2 b}$. We defined 5-oxo-2,3-dihydro- $10 \mathrm{~b} H$-[1,3]thiazolo[3,2c][1,3]benzoxazine-3-carboxylic acid $\mathbf{1 1}$ as our target molecule (Scheme 3 ). The chemistry of $[1,3]$ thiazolo[3,2$c][1,3]$ benzoxazines is an area of considerable interest since some derivatives show biological activity namely immunoacitvating action which makes this synthesis more appealing. ${ }^{8}$
The synthetic strategy is outlined in Scheme 3. Thiazolidine 8 was prepared by condensing L-cysteine methyl ester hydrochloride with salicylaldehyde in presence of potassium hydrogen carbonate. Our approach to construct the six-membered ring was to react methyl 2-(2-hydroxyphenyl)thiazolidine-4-carboxylate 8 with phosgene. The reaction was carried out at room temperature and after $6 \mathrm{~h}$ a product was isolated in $67 \%$ yield. Although it was expected to obtain directly the cyclization product, the characterisation data allow us to conclude that we were in the presence of methyl $(2 R, 4 R)-N$-chlorocarbonyl-2-(2-hydroxyphenyl)thiazolidine-4-carboxylate 9. This showed $[\alpha]_{\mathrm{D}}^{25}=+197(c=0.1, \mathrm{EtOH})$. Thus, the reaction conditions used led to a diastereoselective $\mathrm{N}$-acylation of thiazolidine $\mathbf{8}$.

It is known that NMR spectra of $N$-acylthiazolidines at ambient temperature are usually complicated by the existence of rotamers. ${ }^{1,9}$ In agreement with this we found that the ${ }^{1} \mathrm{H}$ and ${ }^{13} \mathrm{C}$ NMR spectra of thiazolidine 9 recorded at room temperature, showed two sets of signals.

The structure of methyl $(2 R, 4 R)-N$-chlorocarbonyl-2-(2hydroxyphenyl)thiazolidine-4-carboxylate 9 was confirmed by X-ray crystallography (Fig. 2). The absolute structure was determined by a Flack analysis (1358 Friedel pairs, $\eta=-0.16(9))$ that unambiguously assigns the $R, R$ configuration to the chiral centers $\mathrm{C} 2$ and $\mathrm{C} 4$.

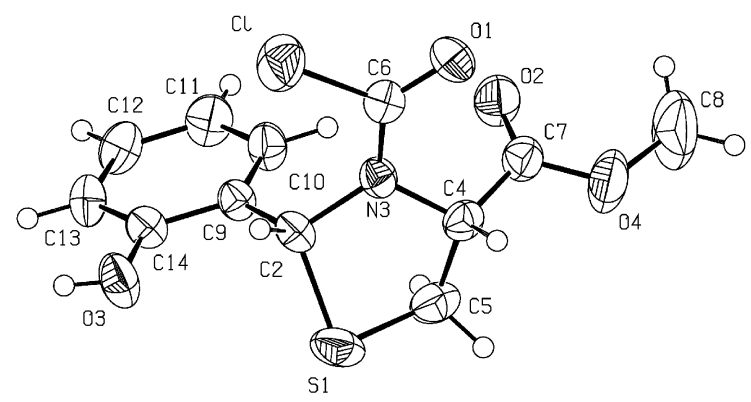

Figure 2. X-ray structure of compound 9

The thiazolidine ring adopts a twisted conformation around atom N3. The puckering parameters as defined by Cremer and Pople ${ }^{10}$ are $q_{2}=0.503(3) \AA, \phi_{2}=346.0(4)^{\circ}$, the $\varphi_{2}$ value<smiles>COC(=O)[C@H](N)CS</smiles><smiles>CC(=O)[C@H]1CS[C@@H](c2ccccc2O)N1</smiles>

$8,60 \%$

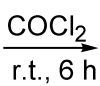<smiles>COC(=O)N1[C@H](C(=O)Cl)CS[C@H]1c1ccccc1O</smiles>

$\mathbf{9}, 67 \% \quad[\alpha]_{D}^{25}=+197$
1. Lil

2. $\mathrm{HCl}$ aq.<smiles>O=C(O)[C@@H]1CS[C@@H]2c3ccccc3OC(=O)N12</smiles>

$10,87.5 \%[\alpha]_{D}^{25}=+98$

$11,71 \% \quad[\alpha]_{D}^{25}=+231$

Scheme 3. 
for the pure twisted conformation being $342^{\circ}$. There is an approximate $\mathrm{C}_{2}$ axis running through $\mathrm{N} 3$ and the middle of the $\mathrm{S} 1-\mathrm{C} 5$ bond, the $C_{2}$ asymmetry parameter being $4.2(3)^{\circ}$. The exocyclic angles around the N3 atom show a large asymmetry; the sum of the valence angles around this atom is $358.9^{\circ}$ indicating an insignificant degree of pyramidalization.

The least-squares planes of the hydroxyphenyl group and thiazolidine ring make an angle of $48.6(1)^{\circ}$. The methyl carboxylate substituent is in bissectional position with respect to the ring plane. The torsion angle $\mathrm{O} 2-\mathrm{C} 7-\mathrm{C} 4-\mathrm{C} 5$ is $86.0(4)^{\circ}$. The chlorocarbonyl group is planar but slightly titled with respect to the least squares plane defined by atoms N3, C2, C4 and C6 (the torsion angle $\mathrm{C} 2-\mathrm{N} 3-\mathrm{C} 6-$ $\mathrm{Cl}$ is $\left.-4.5(4)^{\circ}\right)$.

We studied the thermolysis of $(2 R, 4 R)-N$-chlorocarbonyl-2(2-hydroxyphenyl)thiazolidine-4-carboxylate 9 as a way to the corresponding cyclization product. However, even when a solution of 9 in sulpholane was heated at reflux did not lead to the desired product. The synthesis of methyl $(3 R, 10 \mathrm{~b} R)$-5-oxo-2,3-dihydro- $10 \mathrm{~b} H$-[1.3] thiazolo[3,2c] [1,3]benzoxazine-3-carboxylate $\mathbf{1 0}(87.5 \%)$ was achieved when thiazolidine 9 was treated with DBU (with DBN 10 was obtained in $76 \%$ yield). This new tricyclic compound $\mathbf{1 0}$ was obtained as single stereoisomer with $[\alpha]_{\mathrm{D}}^{25}=+98$ (Scheme 3).

The $(3 R, 10 \mathrm{~b} R)-5$-oxo-2,3-dihydro- $10 \mathrm{~b} H$-[1.3]thiazolo[3,2c] $[1,3]$ benzoxazine-3-carboxylic acid $\mathbf{1 1}$ was obtained in $71 \%$ yield by reacting compound $\mathbf{1 0}$ with lithium iodide in ethyl acetate followed by treatment with aqueous $\mathrm{HCl}$ (Scheme 3).

Attempts to generate the corresponding münchnone from 5-oxo-2,3-dihydro-10b $H$-[1.3]thiazolo[3,2-c][1,3]benzoxazine derivative $\mathbf{1 1}$ in presence of DMAD did not lead to positive results. However, the thermolysis of $\mathbf{1 1}$ in acetic anhydride, carried out in a sealed tube, led to the synthesis of 5-acetyl-2-phenyl-2,3-dihydrothiazole $\mathbf{1 4}$ in low yield (Scheme 4). The formation of this product can be rationalised as involving a double decarboxylation giving 12 which is converted into 2,3-dihydrothiazole $\mathbf{1 3}$ through prototropy. Acylation of this intermediate gives compound 14.

\section{Conclusion}

In conclusion, we report a synthetic methodology to new tricyclic isoindole derivatives, 3-methylene-2,5-dioxo$3 H, 9 \mathrm{bH}$-oxazolo[2,3-a]isoindoles through the thermolysis of $(3 R, 9 \mathrm{~b} S)-5$-oxo-2,3,5,9b-tetrahydrothiazolo[2,3- $a$ ]isoindole-3-carboxylic acids in acetic anhydride.

Chiral (9bS)-5-oxo-2,3,5,9b-tetrahydrothiazolo[2,3- $a$ ]isoindoles (7a and $\mathbf{7 b}$ ) were also obtained from the flash vacuum pyrolysis of $(3 R, 9 \mathrm{~b} S)-5$-oxo- $2,3,5,9 \mathrm{~b}$-tetrahydrothiazolo[2,3-a]isoindole-3-carboxylic acids.

The diastereoselective synthesis of $(3 R, 10 \mathrm{~b} R)-5$-oxo-2,3dihydro- $10 \mathrm{~b} H$-[1,3]thiazolo[3,2-c][1,3]benzoxazines (10 and 11) was accomplished and the thermolysis of $\mathbf{1 1}$ in acetic anhydride gave 5-acetyl-2-phenyl-2,3-dihydrothiazole 14.

The work provided a range of isoindoles and thiazolobenzoxazines, compounds with potential biological activity. 5,8

\section{Experimental}

\subsection{General}

${ }^{1} \mathrm{H}$ NMR spectra were recorded on a Bruker AMX300 instrument operating at $300 \mathrm{MHz} .{ }^{13} \mathrm{C}$ spectra were recorded on a Bruker AMX300 instrument operating at 75.5 MHz. The solvent is deuteriochloroform except where indicated otherwise. IR spectra were recorded on a PerkinElmer 1720X FTIR spectrometer. Mass spectra were recorded on a HP GC 6890/MSD5973 instrument under electron impact (EI) except where indicated otherwise. Optical rotations were measured on an Optical Activity AA-5 electrical polarimeter. Microanalyses were performed in the University of Coimbra using a EA 1108-CHNS-O Fisons instrument or in the University of Liverpool using a Carlo-Erba elemental analyser. Mp were recorded on a Reichert hot stage and are uncorrected. Flash column chromatography was performed with Merck 9385 silica as the stationary phase.

4.1.1. Methyl $(3 R, 9 \mathrm{~b} S)-5-0 x 0-2,3,5,9 \mathrm{~b}-$ tetrahydrothiazolo[2,3-a]isoindole-3-carboxylate (1a). L-Cysteine methyl ester hydrochloride $(3.45 \mathrm{~g}, 20 \mathrm{mmol})$ was dissolved in water $(15 \mathrm{~mL})$ and potassium hydrogen carbonate $(2.0 \mathrm{~g}$, $20 \mathrm{mmol}$ ) was added following the addition of a solution of the 2-carboxybenzaldeyde $(3.3 \mathrm{~g}, 22 \mathrm{mmol})$ in ethanol $(15 \mathrm{~mL})$. The reaction mixture was stirred at room temperature for $30 \mathrm{~min}$. The reaction mixture was diluted with water and extracted with dichloromethane. The organic phase was dried and the solvent was evaporated off giving the methyl $(3 R, 9 \mathrm{~b} S)$-5-oxo-2,3,5,9b-tetrahydrothiazolo[2,3a] isoindole-3-carboxylate 1a as a white solid (3.48 g, 71\%). Mp $83.2-85.8^{\circ} \mathrm{C}$ (from ethyl ether), lit. ${ }^{6} 83-86{ }^{\circ} \mathrm{C}$. $\nu_{\max }$

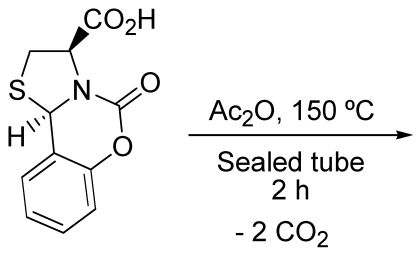

11

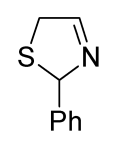

12

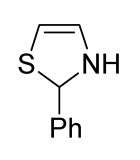

13

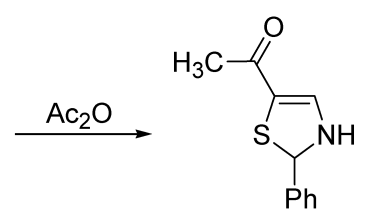

14

Scheme 4. 
(KBr) 1745 and $1710 \mathrm{~cm}^{-1} ; \delta_{\mathrm{H}} 3.59-3.70(2 \mathrm{H}, \mathrm{m}), 3.83$ $(3 \mathrm{H}, \mathrm{s}), 5.25(1 \mathrm{H}, \mathrm{dd}, J=4.9,7.1 \mathrm{~Hz}), 6.08(1 \mathrm{H}, \mathrm{s}), 7.48-$ $7.63(3 \mathrm{H}, \mathrm{m}, \mathrm{Ar}-\mathrm{H}), 7.81-7.83(1 \mathrm{H}, \mathrm{m}, \mathrm{Ar}-\mathrm{H}) ; \mathrm{m} / \mathrm{z} 249$ $\left(\mathrm{M}^{+}, 100 \%\right), 221(8), 190(83), 162(44)$ and $146(12)$. Anal. Calcd for $\mathrm{C}_{12} \mathrm{H}_{11} \mathrm{NO}_{3} \mathrm{~S}$ : C, 57.82; H, 4.45; N, 5.62; S, 12.86 . Found: $\mathrm{C}, \quad 57.72 ; \mathrm{H}, 4.44 ; \mathrm{N}, 5.64 ; \mathrm{S}, 12.48 \%$. $[\alpha]_{\mathrm{D}}^{25}=-400.5\left(c=2.3, \mathrm{CH}_{2} \mathrm{Cl}_{2}\right)$.

4.1.2. Methyl (3R,9bS)-9b-methyl-5-oxo-2,3,5,9btetrahydrothiazolo[2,3-a]isoindole-3-carboxylate (1b). L-Cysteine methyl ester hydrochloride $(0.865 \mathrm{~g}, 5 \mathrm{mmol})$ and sodium acetate $(1.23 \mathrm{~g}, 15 \mathrm{mmol})$ were dissolved in toluene $(50 \mathrm{~mL})$ and a solution of 2-acetylbenzoic acid $(0.825 \mathrm{~g}, 5 \mathrm{mmol})$ in toluene $(50 \mathrm{~mL})$ was added. The reaction mixture was at reflux for $5 \mathrm{~h}$. The solution was washed with water, dried and the solvent was evaporated off. The crude product was purified by flash chromatography [hexane-ethyl acetate $(1: 1)$ ]. Compound 1b was obtained as a white solid $(0.98 \mathrm{~g}, 74.5 \%)$. Mp $128.8-132.1^{\circ} \mathrm{C}$ (from ethyl ether), lit. ${ }^{6} 113-116^{\circ} \mathrm{C}$. $\nu_{\max }(\mathrm{KBr}) 1753$ and $1695 \mathrm{~cm}^{-1} ; \delta_{\mathrm{H}} 1.96\left(3 \mathrm{H}, \mathrm{s}, \mathrm{CO}_{2} \mathrm{Me}\right), 3.83(1 \mathrm{H}, \mathrm{dd}$, $J=8.7 \mathrm{~Hz}), 3.85(3 \mathrm{H}, \mathrm{s}), 3.95(1 \mathrm{H}, \mathrm{dd}, J=6.5 \mathrm{~Hz}), 5,15$ $(1 \mathrm{H}, \mathrm{dd}, J=6.5,8.7 \mathrm{~Hz}), 7.48-7.54(2 \mathrm{H}, \mathrm{m}, \mathrm{ArH}), 7.60-$ $7.63(1 \mathrm{H}, \mathrm{m}, \mathrm{ArH}), 7.80-7.82(1 \mathrm{H}, \mathrm{m}, \mathrm{ArH}) .[\alpha]_{\mathrm{D}}^{25}=-328.7$ $\left(c=1.75, \mathrm{CH}_{2} \mathrm{Cl}_{2}\right)$.

\subsection{General procedure for the synthesis of 5-oxo- 2,3,5,9b-tetrahydrothiazolo[2,3-a]isoindole-3-carboxylic acids $2 a$ and $2 b$}

The $(3 R, 9 \mathrm{~b} S)$-5-oxo-2,3,5,9b-tetrahydrothiazolo[2,3-a]isoindole-3-carboxylate (1a or $\mathbf{1 b})(1 \mathrm{mmol})$ and LiI $(4 \mathrm{mmol})$ were dissolved in ethyl acetate $(1.3 \mathrm{~mL})$. The reaction mixture was protected from light and heated at reflux for $6 \mathrm{~h}$. Water was added $(5 \mathrm{~mL})$ and the solution was acidified with $\mathrm{HCl} 1 \mathrm{M}$ and extracted with ethyl acetate. The organic phase was washed with water and with saturated aqueous solution of $\mathrm{NaCl}$. The organic solvent was evaporated off. To the residue a saturated aqueous solution of $\mathrm{NaHCO}_{3}$ was added and the solution was washed with dichloromethane. The aqueous solution was acidified with concentrated $\mathrm{HCl}$ and extracted with ethyl acetate. The organic phase was dried and the solvent was evaporated off giving the desired product.

4.2.1. $(3 R, 9 \mathrm{~b} S)-5-0 \times 0-2,3,5,9 \mathrm{~b}-$ tetrahydrothiazolo[2,3a]isoindole-3-carboxylic acid 2a. The title compound was obtained as a white solid $(91 \%)$. Mp $156.1-157.9^{\circ} \mathrm{C}$ (from ethyl ether), lit. ${ }^{4} 161-162{ }^{\circ} \mathrm{C} . \delta_{\mathrm{H}}\left(\mathrm{CDCl}_{3} / \mathrm{DMSO}-d_{6}\right)$ $3.71(1 \mathrm{H}, \mathrm{dd}, J=7.4,12.0 \mathrm{~Hz}), 3.81(1 \mathrm{H}, \mathrm{dd}, J=6.6$, $12.0 \mathrm{~Hz}), 5.03(1 \mathrm{H}$, approx. $\mathrm{t}, J=7.0 \mathrm{~Hz}), 6.06(1 \mathrm{H}, \mathrm{s})$, $7.51-7.58$ (3H, m, Ar-H), 7.85-7.88 (1H, m, Ar-H); m/z [compound 2a treated with $\mathrm{CH}_{2} \mathrm{~N}_{2}$ ] 249 [( $\left(\mathrm{M}^{+}-\mathrm{H}\right), 100 \%$ ], $221(5)$ and 190 (95). Anal. Calcd for $\mathrm{C}_{11} \mathrm{H}_{9} \mathrm{NO}_{3} \mathrm{~S}: \mathrm{C}, 56.16$; H, 3.86; N, 5.95; S, 13.63. Found: C, 55.87; H, 3.92; N, 5.81; S, $13.92 \%$. $[\alpha]_{\mathrm{D}}^{25}=-343(c=0.1, \mathrm{EtOH})$.

4.2.2. $(3 R, 9 \mathrm{~b} S)-9 \mathrm{~b}-$ Methyl-5-oxo-2,3,5,9b-tetrahydrothiazolo[2,3-a]isoindole-3-carboxylic acid 2b. The title compound was obtained as a white solid (85\%). Mp 162.3$164.9^{\circ} \mathrm{C}$ (from ethyl ether). $\delta_{\mathrm{H}} 1.97(3 \mathrm{H}, \mathrm{s}), 3.88(1 \mathrm{H}, \mathrm{dd}$, $J=8.5,12.3 \mathrm{~Hz}), 4.05(1 \mathrm{H}, \mathrm{dd}, J=7.8,12.3 \mathrm{~Hz}), 5.01(1 \mathrm{H}$, approx. t, $J=8.2 \mathrm{~Hz}), 7.50-7.56(2 \mathrm{H}, \mathrm{m}, \mathrm{ArH}), 7.63-7.69$
(1H, m, ArH), 7.81-7.84 (1H, m, ArH). Anal. Calcd for $\mathrm{C}_{12} \mathrm{H}_{11} \mathrm{NO}_{3} \mathrm{~S}: \mathrm{C}, 57.82 ; \mathrm{H}, 4.45 ; \mathrm{N}, 5.62 ; \mathrm{S}, 12.86$. Found: C, 57.69; H, 4.42; N, 5.33; S, 12.33\%. $[\alpha]_{\mathrm{D}}^{25}=-363(c=0.1$, $\mathrm{MeOH})$.

4.3. General procedure for the synthesis of 3-methylene2,5-dioxo-3H,9bH-oxazolo[2,3-a]isoindoles $6 \mathrm{a}$ and $6 \mathrm{~b}$

A solution of 5-oxo-2,3,5,9b-tetrahydrothiazolo[2,3- $a$ ]isoindole-3-carboxylic acid (2a or $\mathbf{2 b})(3 \mathrm{mmol})$ in $\mathrm{Ac}_{2} \mathrm{O}$ $(5 \mathrm{~mL})$ was heated, in a sealed tube, at $150{ }^{\circ} \mathrm{C}$ for $4 \mathrm{~h}$. The reaction was cooled to room temperature and was diluted with dichloromethane $(50 \mathrm{~mL})$. The organic phase was washed with saturated aqueous solution of $\mathrm{NaHCO}_{3}$ and with water, dried $\left(\mathrm{MgSO}_{4}\right)$ and evaporated off. The crude product was purified by flash chromatography [ethyl acetate-hexane (1:2)].

4.3.1. 3-Methylene-2,5-dioxo-3H,9b $\mathrm{H}$-oxazolo[2,3-a]isoindole 6a. The title compound was obtained as a white solid (37\%). Mp $174.2-176.0^{\circ} \mathrm{C}$ (from ethyl ether). $\delta_{\mathrm{H}} 5.93(1 \mathrm{H}$, d, $J=1.4 \mathrm{~Hz}), 5.96(1 \mathrm{H}, \mathrm{d}, J=1.4 \mathrm{~Hz}), 6.51(1 \mathrm{H}, \mathrm{s}), 7.68-$ $7.79(3 \mathrm{H}, \mathrm{m}, \mathrm{Ar}-\mathrm{H}), 7.95-7.97(1 \mathrm{H}, \mathrm{Ar}-\mathrm{H}) ; \delta_{\mathrm{C}} 88.0,107.9$, $125.1,125.5,130.1,131.7,131.9,134.4,141.1,165.2$, 169.3; $\mathrm{m} / \mathrm{z} 201\left(\mathrm{M}^{+}, 33 \%\right), 172(4), 157$ (41) and $133(100)$.

4.3.2. 9b-Methyl-3-methylene-2,5-dioxo-3H,9bH-oxazolo $[2,3-a]$ isoindole $\mathbf{6 b}$. The title compound was obtained as a light yellow solid (64\%). Mp 145.4-147.6 ${ }^{\circ} \mathrm{C}$ (from ethyl ether). $\delta_{\mathrm{H}} 2.00(3 \mathrm{H}, \mathrm{s}), 5.88(1 \mathrm{H}, \mathrm{d}, J=0.7 \mathrm{~Hz}), 6.03$ $(1 \mathrm{H}, \mathrm{d}, J=0.7 \mathrm{~Hz}), 7.60-7.65(2 \mathrm{H}, \mathrm{m}, \mathrm{Ar}-\mathrm{H}), 7.71-7.76$ (1H, m, Ar-H), 7.95-8.00 (1H, Ar-H); m/z $216\left(\mathrm{MH}^{+}, 3 \%\right)$, $198(2), 188(19)$ and $171(100) ; \delta_{\mathrm{C}} 32.2,73.8,108.0,122.6$, $125.3,129.0,130.2,134.0,135.8,148.0,167.0,192.3$.

4.4. General procedure for the flash vacuum pyrolysis of 5-oxo-2,3,5,9b-tetrahydrothiazolo[2,3-a]isoindole-3carboxylic acids $2 \mathrm{a}$ and $\mathbf{2 b}$

Pyrolysis of 5-oxo-2,3,5,9b-tetrahydrothiazolo[2,3-a]isoindole-3-carboxylic acids 2aor 2 b $(1.5 \mathrm{mmol})$ at $600{ }^{\circ} \mathrm{C} / 3 \times 10^{-2}-4 \times 10^{-2} \mathrm{mbar}$ onto a surface cooled at $-196^{\circ} \mathrm{C}$ over a period of $2 \mathrm{~h}$ gave a yellowish pyrolysate [The rate of volatilisation of the starting material was controlled by the use of a Kugelrohr oven which heated the sample at $200{ }^{\circ} \mathrm{C}$ ]. After cooling to room temperature the pyrolysate was removed from the cold finger with dichloromethane. The solvent was removed in vacuo and the residue purified by flash chromatography $\left[\mathrm{SiO}_{2}\right.$, ethylacetate-hexane $(1: 2)]$ for $\mathbf{7 a}$ and $\left[\mathrm{SiO}_{2}\right.$, ethyl-acetatehexane (1:3)] for $\mathbf{7 b}$.

4.4.1. (9bS)-5-Oxo-2,3,5,9b-tetrahydrothiazolo[2,3-a]isoindole $7 \mathbf{a}$. The title compound was obtained as a white solid (29\%). Mp 99.6-100.3 ${ }^{\circ} \mathrm{C}$ (from ethyl ether/hexane), lit. ${ }^{9} 97-$ $100{ }^{\circ} \mathrm{C} . \delta_{\mathrm{H}} 3.35-3.44(3 \mathrm{H}, \mathrm{m}), 4.44-4.45(1 \mathrm{H}, \mathrm{m}), 5.88(1 \mathrm{H}, \mathrm{s})$, 7.49-7.56 (2H, m, Ar-H), 7.57-7.60 (1H, m, Ar-H), 7.80-7.82 $(1 \mathrm{H}, \mathrm{m}, \mathrm{Ar}-\mathrm{H}) ; \delta_{\mathrm{C}} 36.5,44.5,66.0,123.2,124.3,129.2,131.1$, 132.6, 145.1, 170.8; m/z $191\left(\mathrm{M}^{+}, 84 \%\right), 163$ (12), 145 (100), 117 (39), $90(28)$ and $76(14) .[\alpha]_{\mathrm{D}}^{25}=-341\left(c=0.1, \mathrm{CH}_{2} \mathrm{Cl}_{2}\right)$.

4.4.2. (9bS)-9b-Methyl-5-oxo-2,3,5,9b-tetrahydrothiazolo $[2,3-a]$ isoindole $7 \mathbf{b}$. The title compound was obtained 
as an yellow oil $(21 \%) . \delta_{\mathrm{H}} 1.92(3 \mathrm{H}, \mathrm{s}), 3.35-3.50(3 \mathrm{H}, \mathrm{m})$, 4.54-4.61 (1H, m), 7.45-7.51 (2H, m, Ar-H), 7.57-7.63 (1H, m, Ar-H), 7.76-7.79 (1H, m, Ar-H); m/z $205\left(\mathrm{M}^{+}\right.$, 100\%), 190 (21), 158 (68) and $146(66) .[\alpha]_{\mathrm{D}}^{25}=-69$ $\left(c=0.15, \mathrm{CH}_{2} \mathrm{Cl}_{2}\right)$.

4.4.3. Methyl 2-(2-hydroxyphenyl)thiazolidine-4-carboxylate 8. L-Cysteine methyl ester hydrochloride $(3.45 \mathrm{~g}$, $20 \mathrm{mmol})$ was dissolved in water $(15 \mathrm{~mL})$ and potassium hydrogen carbonate $(2.0 \mathrm{~g}, 20 \mathrm{mmol})$ was added following the addition of a solution of the salicylaldehyde $(2.68 \mathrm{~g}$, $22 \mathrm{mmol})$ in ethanol $(15 \mathrm{~mL})$. The reaction mixture was stirred at room temperature for $30 \mathrm{~min}$. The reaction mixture was diluted with water and extracted with dichloromethane. The organic phase was dried and the solvent was evaporated off giving the methyl 2-(2-hydroxyphenyl)thiazolidine-4-carboxylate 8 (60\%). Mp 66.7$68.0{ }^{\circ} \mathrm{C}$ (from ethyl ether). $\nu$ (KBr) 3277 and $1736 \mathrm{~cm}^{-1}$; $\delta_{\mathrm{H}}$ (two diastereoisomers, ratio $\left.73: 27\right) 3.20-3.25(1 \mathrm{H}, \mathrm{m})$, $3.40-3.47(1 \mathrm{H}, \mathrm{m}), 3.78$ and $3.83(3 \mathrm{H}, 2 \mathrm{xs}), 4.07-4.19(1 \mathrm{H}$, $\mathrm{m}), 5.62$ and $5.92(1 \mathrm{H}, 2 \mathrm{xd}, J=5.7,4.3 \mathrm{~Hz}$ respectively), 6.79-6.94 (2H, m, Ar-H), 7.16-7.26 (2H, m, Ar-H); m/z $239\left(\mathrm{M}^{+}, 19 \%\right), 224$ (10), 193 (21), 180 (36), 163 (71), 146 (13) and 132 (100). Anal. Calcd for $\mathrm{C}_{11} \mathrm{H}_{13} \mathrm{NO}_{3} \mathrm{~S}$ : C, 55.21; H, 5.48; N, 5.85; S, 13.40. Found: C, 55.42; H, 5.72; N, $5.81 ; \mathrm{S}, 13.02 \%$.

4.4.4. Methyl $(2 R, 4 R)-N$-chlorocarbonyl-2-(2-hydroxyphenyl)thiazolidine-4-carboxylate 9 . The methyl 2-(2hydroxyphenyl)thiazolidine-4-carboxylate 8 (3.75 g, $15.7 \mathrm{mmol})$ was dissolved in dichloromethane $(20 \mathrm{~mL})$ and potassium hydrogen carbonate $(1.57 \mathrm{~g}, 15.7 \mathrm{mmol})$ and a solution of the phosgene in toluene $(10 \mathrm{~mL}, 18.84 \mathrm{mmol})$ was added dropwise. The reaction mixture was stirred at room temperature for $6 \mathrm{~h}$. The reaction mixture was diluted with water and extracted with ethyl acetate. The organic phase was dried and the solvent was evaporated off giving the methyl $(2 R, 4 R)-N$-chlorocarbonyl-2-(2-hydroxyphenyl)thiazolidine-4-carboxylate $\mathbf{9}$ as a white solid (67\%). Mp 145.2-146.9 ${ }^{\circ} \mathrm{C}$. $\nu(\mathrm{KBr}) 3285,1746$ and $1698 \mathrm{~cm}^{-1} . \delta_{\mathrm{H}}$ (two rotamers) $\left(\mathrm{CDCl}_{3} / \mathrm{DMSO}-d_{6}\right) 3.22-$ $3.41(2 \mathrm{H}, \mathrm{m}), 3.86$ and $3.89(3 \mathrm{H}, 2 \mathrm{xs}), 4.83$ and $5.07(1 \mathrm{H}$, $\mathrm{dd}, J=6.4,9.4 \mathrm{~Hz}$ and approx. $\mathrm{t}, J=6.4 \mathrm{~Hz}$, respectively), 6.49 and $6.56(1 \mathrm{H}, 2 \mathrm{xs}), 6.83-6.90(2 \mathrm{H}, \mathrm{m}, \mathrm{Ar}-\mathrm{H}), 7.10-$ $7.18(1 \mathrm{H}, \mathrm{m}, \mathrm{Ar}-\mathrm{H}), 7.79-7.86(1 \mathrm{H}, \mathrm{m}, \mathrm{Ar}-\mathrm{H}) ; \delta_{\mathrm{C}}$ (two rotamers): major: $\left(\mathrm{CDCl}_{3} / \mathrm{DMSO}-d_{6}\right)$ 31.7, 52.7, 63.8, 66.1, $115.0,119.1,125.6,126.4,128.7,147.7,153.3,168.8$; minor: $32.4,52.9,64.2,66.8,115.3,119.2,124.2,126.0$, 128.9, 147.7, 153.7, 169.5. $\mathrm{m} / \mathrm{z} 265\left[\left(\mathrm{M}^{+}-\mathrm{HCl}\right), 4 \%\right], 264$ (6), 206 (15) and 179 (100). Anal. Calcd for $\mathrm{C}_{12} \mathrm{H}_{12} \mathrm{NO}_{4} \mathrm{SCl}$ : C, 47.77; H, 4.01; N, 4.64; S, 10.62. Found: C, 47.89; H, $4.23 ; \mathrm{N}, 4.57 ; \mathrm{S}, 10.93 \% .[\alpha]_{\mathrm{D}}^{25}=+197\left(c=0.1, \mathrm{CH}_{3^{-}}\right.$ $\left.\mathrm{COCH}_{3}\right)$.

4.4.5. Methyl (3R,10bR)-5-oxo-2,3-dihydro-10bH$[1,3]$ thiazolo[3,2-c][1,3]benzoxazine-3-carboxylate 10. The methyl $(2 R, 4 R)-N$-chlorocarbonyl-2-(2-hydroxyphenyl)thiazolidine-4-carboxylate $9(0.84 \mathrm{~g}, 2.8 \mathrm{mmol})$ was dissolved in ethyl acetate $(15 \mathrm{~mL})$. DBU $(2 \mathrm{mmol})$ was added and the reaction mixture was heated at $50{ }^{\circ} \mathrm{C}$ for $2 \mathrm{~h}$. Water was added $(15 \mathrm{~mL})$ and the solution was extracted with ethyl acetate. The organic phase was washed with water and dried. The residue obtained upon removal of the solvent was purified by column chromatography [ethyl acetate-hexane (1:1)] giving compound $\mathbf{1 0}$ as a white solid (87.5\%). Mp 127.4-129.1 ${ }^{\circ} \mathrm{C}$ (from ethyl acetate-hexane). $\delta_{\mathrm{H}} 3.44(1 \mathrm{H}, \mathrm{dd}, J=0.94,12.7 \mathrm{~Hz}), 3.63(1 \mathrm{H}, \mathrm{dd}, J=7.5$, $12.7 \mathrm{~Hz}), 3.74(3 \mathrm{H}, \mathrm{s}), 4.88(1 \mathrm{H}, \mathrm{dd}, J=1.1,7.5 \mathrm{~Hz}), 6.05$ $(1 \mathrm{H}, \mathrm{s}), 7.12-7.22(3 \mathrm{H}, \mathrm{m}, \mathrm{Ar}-\mathrm{H}), 7.31-7.44(1 \mathrm{H}, \mathrm{m}$, Ar-H); $\delta_{\mathrm{C}} 34.0,53.0,62.1,63.0,116.5,119.2,125.1,125.7$, 130.2, 148.2, 149.0, 169.0; $\mathrm{m} / \mathrm{z} 265\left(\mathrm{M}^{+}, 5 \%\right), 206(17)$ and 179 (100). Anal. Calcd for $\mathrm{C}_{12} \mathrm{H}_{11} \mathrm{NO}_{4} \mathrm{~S}: \mathrm{C}, 54.33$; H, 4.18; N, 5.28. Found: C, 53.98; H, 4.43; N, 5.14\%. $[\alpha]_{\mathrm{D}}^{25}=+98$ $\left(c=0.1, \mathrm{CH}_{2} \mathrm{Cl}_{2}\right)$.

4.4.6. $(3 R, 10 \mathrm{~b} R)-5-O x 0-2,3-\operatorname{dihydro-10b} H$ - $[1,3]$ thiazolo[3,2-c] [1,3]benzoxazine-3-carboxylic acid 11. The methyl $(3 R, 10 \mathrm{~b} R)-5$-oxo-2,3-dihydro- $10 \mathrm{~b} H$-[1.3]thiazolo[3,2-c][1,3]benzoxazine-3-carboxylate $\mathbf{1 0} \quad(0.235 \mathrm{~g}$, $1 \mathrm{mmol})$ and LiI (4 mmol) were dissolved in ethyl acetate $(1.3 \mathrm{~mL})$. The reaction mixture was protected from light and heated at reflux for $6 \mathrm{~h}$. Water was added $(5 \mathrm{~mL})$ and the solution was acidified with $\mathrm{HCl} 1 \mathrm{M}$ and extracted with ethyl acetate. The organic phase was washed with water and with saturated aqueous solution of $\mathrm{NaCl}$. The organic solvent was evaporated off. To the residue a saturated aqueous solution of $\mathrm{NaHCO}_{3}$ was added and the solution was washed with DCM. The aqueous solution was acidified with concentrated $\mathrm{HCl}$ and extracted with ethyl acetate. The residue obtained upon removal of the solvent was purified by column chromatography [ethyl acetate-hexane (1:1)] giving compound 11 light yellow solid (71\%). Mp 173.2$175.3^{\circ} \mathrm{C}$ (from ethyl ether-hexane). $\delta_{\mathrm{H}}\left(\mathrm{CDCl}_{3} / \mathrm{DMSO}-d_{6}\right)$ $3.46-3.51(1 \mathrm{H}, \mathrm{m}), 3.64(1 \mathrm{H}, \mathrm{dd}, J=7.7,12.7 \mathrm{~Hz}), 4.81$ $(1 \mathrm{H}, \mathrm{dd}, J=1.2,7.6 \mathrm{~Hz}), 6.07(1 \mathrm{H}, \mathrm{s}), 7.09-7.21(3 \mathrm{H}, \mathrm{m}$, $\mathrm{ArH}), 7.33-7.38(1 \mathrm{H}, \mathrm{m}, \mathrm{ArH}) ; \delta_{\mathrm{C}}\left(\mathrm{CDCl}_{3} / \mathrm{DMSO}-d_{6}\right) 36.6$, 64.6, 65.6, 119.0, 122.0, 127.5, 128.4, 132.6, 148.5, 151.7, $172.7 ; \mathrm{m} / \mathrm{z}$ [compound $\mathbf{1 1}$ treated with $\mathrm{CH}_{2} \mathrm{~N}_{2}$ ] 264 $\left[\left(\mathrm{M}^{+}-\mathrm{H}\right), 5 \%\right], 206(14)$ and 179 (100). Anal. Calcd for $\mathrm{C}_{11} \mathrm{H}_{9} \mathrm{NO}_{4} \mathrm{~S}: \mathrm{C}, 52.58 ; \mathrm{H}, 3.61 ; \mathrm{N}, 5.57 ; \mathrm{S}, 12.76$. Found: C, $52.41 ; \mathrm{H}, 3.38 ; \mathrm{N}, 5.58 ; \mathrm{S}, 12.83 \% .[\alpha]_{\mathrm{D}}^{25}=+231(c=0.1$, $\mathrm{MeOH})$.

4.4.7. 5-Acetyl-2-phenyl-2,3-dihydrothiazole 14. A solution of $(3 R, 10 \mathrm{~b} R)-5$-oxo-2,3-dihydro- $10 \mathrm{~b} H$-[1,3]thiazolo[3,2-c][1,3]benzoxazine-3-carboxylic acid $11(0.75 \mathrm{~g}$, $3 \mathrm{mmol})$ in $\mathrm{Ac}_{2} \mathrm{O}(5 \mathrm{~mL})$ was heated, in a sealed tube, at $150{ }^{\circ} \mathrm{C}$ for $2 \mathrm{~h}$. The reaction was cooled to room temperature and was diluted with dichloromethane $(50 \mathrm{~mL})$. The organic phase was washed with saturated aqueous solution of $\mathrm{NaHCO}_{3}$ and with water, dried $\left(\mathrm{MgSO}_{4}\right)$ and evaporated off. The crude product was purified by flash chromatography [ethyl acetate-hexane (1:3)] giving compound $\mathbf{1 4}$ as a white solid (4\%). Mp $73.5-74.5^{\circ} \mathrm{C}$ (from dichloromethanehexane). $\nu(\mathrm{KBr}) 1745,1690$ and $1639 \mathrm{~cm}^{-1} \cdot \delta_{\mathrm{H}} 2.40$ $(1 \mathrm{H}, \mathrm{s}), 4.70(1 \mathrm{H}, \mathrm{s}), 4.75(1 \mathrm{H}, \mathrm{m}, \mathrm{NH}), 6.73(1 \mathrm{H}, \mathrm{s}), 7.10-$ $7.22(3 \mathrm{H}, \mathrm{m}, \mathrm{Ar}-\mathrm{H}), 7.32-7.39(2 \mathrm{H}, \mathrm{m}, \mathrm{Ar}-\mathrm{H}) ; \delta_{\mathrm{C}} 30.6,56.9$, 97.4, 116.3, 120.7, 125.3, 125.4, 130.2, 130.3, 148.5, 194.3; $\mathrm{m} / \mathrm{z}\left(\mathrm{CI}-\mathrm{CH}_{4}\right) 206\left[\left(\mathrm{MH}^{+}\right), 28 \%\right], 137$ (5) and 75 (100).

\subsection{X-ray structure determination of methyl $(3 R, 9 \mathrm{bS})-5$ - oxo-2,3,5,9b-tetrahydrothiazolo[2,3-a]isoindole-3- carboxylate 1a}

Crystal data. $\mathrm{C}_{12} \mathrm{H}_{11} \mathrm{NO}_{3} \mathrm{~S}, M=249.28$, tetragonal, space group $P 4_{1} 2{ }_{1}$ (\#92), $a=b=9.424(8), c=26.209(12) \AA$, 
$V=2390.1(11) \AA^{3}, Z=8, D_{\mathrm{c}}=1.386 \mathrm{~g} \mathrm{~cm}^{-3}, \quad F_{000}=1040$, $\mu=2.454 \mathrm{~mm}^{-1}, \quad T=296 \mathrm{~K}$. Number of independent intensities 2294 from transparent, colourless prism, $0.39 \times 0.20 \times 0.15 \mathrm{~mm}^{3}$. $\Psi$-scan absorption correction applied, $T_{\min }=0.888, T_{\max }=0.986$. No significant crystal decay detected.

Data collection. X-ray measurements were performed on a Enraf-Nonius MACH3 diffractometer using $\omega-2 \theta$ scans up to $\theta_{\max }=71.51^{\circ}$.

Structure solution and refinement. The structure was solved using methods using SHELXS97. $R=0.0344$ for 2116 reflections with $I>2 \sigma, R_{\mathrm{w}}=0.0888$ for 2294 reflections used in the refinement and 156 variable parameters. $\mathrm{H}$-atoms were placed at calculated positions except those of the methyl group which were determined from a Fourier difference synthesis and refined as riding on their parent atoms using SHELXL97 defaults.

4.6. X-ray structure determination of methyl $(2 R, 4 R)-N$ chlorocarbonyl-2-(2-hydroxyphenyl)thiazolidine-4carboxylate 9

Crystal data. $\mathrm{C}_{12} \mathrm{H}_{12} \mathrm{ClNO}_{4} \mathrm{~S}, M=301.74$, orthorhombic, space group $P 22_{1} 2_{1} \quad(\# 19), \quad a=8.7424(16) \AA, \quad b=$ 10.1480(7), $\quad c=15.857(3) \AA, \quad V=1406.8(4) \AA^{3}, \quad Z=4$, $D_{\mathrm{c}}=1.425 \mathrm{~g} \mathrm{~cm}^{3}, \quad F_{000}=624, \quad \mu=0.428 \mathrm{~mm}^{-1}, \quad T=$ 296 K. Number of independent intensities: 3210 from transparent, colourless prism, $0.37 \times 0.20 \times 0.15 \mathrm{~mm}^{3}$. $\psi$-scan absorption correction applied, $T_{\min }=0.980$, $T_{\max }=0.961$. No significant crystal decay detected.

Data collection. X-ray measurements were performed on a Enraf-Nonius CAD-4 diffractometer using $\omega-2 \theta$ scans up to $\theta_{\max }=27.44^{\circ}$.

Structure solution and refinement. The structure was solved using direct methods using SHELXS97. $R=0.0409$ for 2182 reflections with $I>2, R_{\mathrm{w}}=0.0952$ for 3210 reflections used in the refinement and 175 variable parameters. H-atoms were placed at calculated positions except those of the methyl group which were determined from a Fourier difference synthesis and refined as riding on their parent atoms using SHELXL97 defaults.

\section{Acknowledgements}

Financial support from Chymiotechnon and Fundação para a Ciência e a Tecnologia (POCTI/36137/QUI/2000) is gratefully acknowledged.

\section{References and notes}

1. (a) Pinho e Melo, T. M. V. D.; Barbosa, D. M.; Ramos, P. J. R. S.; Rocha Gonsalves, A. M. d'A.; Gilchrist, T. L.; Beja, A. M.; Paixão, J. A.; Silva, M. R.; Alte da Veiga, L. J. Chem. Soc., Perkin Trans. 1 1999, 1219-1223. (b) Pinho e Melo, T. M. V. D.; Soares, M. I. L.; Barbosa, D. M.; Rocha Gonsalves, A. M. d'A.; Paixão, J. A.; Beja, A. M.; Silva, M. R.; Alte da Veiga, L. Tetrahedron 2000, 56, 3419-3424. (c) Pinho e Melo, T. M. V. D.; Soares, M. I. L.; Rocha Gonsalves, A. M. d'A.; Paixão, J. A.; Beja, A. M.; Silva, M. R.; Alte da Veiga, L.; Pessoa, J. C. J. Org. Chem. 2002, 67, 4045-4054. (d) Pinho e Melo, T. M. V. D.; Gomes, C. S. B.; Rocha Gonsalves, A. M. d'A.; Paixão, J. A.; Beja, A. M.; Ramos Silva, M.; Alte da Veiga, L. Tetrahedron 2002, 58, 5093-5102.

2. Pinho e Melo, T. M. V. D.; Santos, C. I. A.; Rocha Gonsalves, A. M. d'A.; Paixão, J. A.; Beja, A. M.; Silva, M. R. Tetrahedron Lett. 2003, 44, 8285-8287.

3. Gilchrist, T. L.; Rocha Gonsalves, A. M. d'A.; Pinho e Melo, T. M. V. D. Tetrahedron 1994, 50, 13709-13724.

4. Oliver, G. L.; Gates, J. W., Jr. J. Am. Chem. Soc. 1958, 702-707.

5. (a) Takahashi, I.; Kawakami, T.; Hirano, E.; Yokota, H.; Kitajima, H. Synlett 1996, 353-355. (b) Mertens, A.; Zilch, H.; König, B.; Schäfer, W.; Poll, T.; Kampe, W.; Seidel, H.; Leser, U.; Leinert, H. J. Med. Chem. 1993, 36, 2526-2535. (c) Schäfer, W.; Friebe, W.-G.; Leinert, H.; Mertens, A.; Poll, T.; Saal, von der W.; Zilch, H.; Nuber, B.; Ziegler, M. L. J. Med. Chem. 1993, 36, 726-732. (d) Clercq, E. J. Med. Chem. 1995, 38, 2491-2517. (e) Allin, S. M.; Vaidya, D. G.; Page, M. I.; Slawin, A. M. Z.; Smith, T. Tetrahedron Lett. 2000, 41, 2219-2222.

6. Allin, S. M.; Vaidya, D. G.; Page, M. I.; Slawin, A. M. Z. ARKIVOC 2000, 1, 151-157.

7. Hiskey, R. G.; Dominianni, S. J. J. Org. Chem. 1965, 30, 1506- 1508 .

8. Matsuda, A. H; Tatezaki, Y. R.; Mizuno, S. H.; Katori, T. T. US4,564,615, SS, Pharmaceutical Co, Japan, 1986.

9. (a) Szilágyi, L.; Györgydeák, Z. J. Am. Chem. Soc. 1979, 101, 427-432. (b) Györgydeák, Z.; Kajtár-Peredy, M.; Kajtár, J.; Kajtár, M. Liebigs Ann. Chem. 1987, 927-934. (c) Benedini, F.; Ferrario, F.; Sala, A.; Sala, L.; Soresinetti, P. A. J. Heterocycl. Chem. 1994, 31, 1343-1347.

10. Cremer, D.; Pople, J. A. J. Am. Chem. Soc. 1975, 97, 1354-1358. 